\title{
Active Disturbance Rejection Fuzzy Controller for Roll Stabilization of Autonomous Underwater Vehicle under Wave Disturbance
}

\author{
Lin-Lin Wang, ${ }^{1,2}$ Hong-Jian Wang, ${ }^{1}$ Li-Xin Pan, ${ }^{3}$ and Jun-Xi Guo ${ }^{4}$ \\ ${ }^{1}$ College of Automation, Harbin Engineering University, Harbin 150001, China \\ ${ }^{2}$ College of Information, Inner Mongolia University of Technology, Hohhot 010080, China \\ ${ }^{3}$ Beijing Institute of Control Engineering, China Academy of Space Technology, Beijing 100190, China \\ ${ }^{4}$ Software College, Harbin Institution of Technology, Harbin 150001, China \\ Correspondence should be addressed to Hong-Jian Wang; 8210045905@sina.com
}

Received 24 January 2015; Revised 23 March 2015; Accepted 30 March 2015

Academic Editor: Driss Boutat

Copyright (C) 2015 Lin-Lin Wang et al. This is an open access article distributed under the Creative Commons Attribution License, which permits unrestricted use, distribution, and reproduction in any medium, provided the original work is properly cited.

Considering the case of autonomous underwater vehicle navigating with low speed near water surface, a new method for designing of roll motion controller is proposed in order to restrain wave disturbance effectively and improve roll stabilizing performance under different sea conditions. Active disturbance rejection fuzzy control is applied, which is based on nonlinear motion model of autonomous underwater vehicle and the principle of zero-speed fin stabilizer. Extended state observer is used for estimation of roll motion state and unknown wave disturbance. Wave moment is counteracted by introducing compensation term into the roll control law which is founded on nonlinear feedback. Fuzzy reasoning is used for parameter adjustment of the controller online. Simulation experiments on roll motion are conducted under different sea conditions, and the results show better robustness improved by active disturbance rejection fuzzy controller of autonomous underwater vehicle navigating near water surface.

\section{Introduction}

AUV (Autonomous Underwater Vehicle) rolls severely if it is navigating near water surface and wave disturbance has an obvious effect on its motion attitude. Violent roll motion often discontinues normal working of AUV and even endangers crew or important equipment [1]. So, it is necessary to study an effective control pattern for solution to the problem of AUV motion attitude control. Moreover, traditional fin stabilizer is hard to generate enough lift when AUV is navigating with low speed [2]. Consequently roll motion is very difficult to control at the moment. Then a new pattern of fin stabilizer working is required to realize effective roll control in low speed navigation. Maritime Research Institute Netherlands, KoopNautic Holland, and Quantum Controls Ltd. have ever cooperated in the research on zerospeed fin stabilizer system [3]. Harbin Engineering University designs and tests zero-speed fin stabilizers [4] since 2005.
Considering the characteristic of AUV motion with low speed near water surface, roll attitude is controlled by zerospeed fin stabilizer which is based on Weis-Fogh device. In this paper, ADRFC (Active Disturbance Rejection Fuzzy Controller) is designed because of its strong capacity for self-adaptation. Compared to traditional PID which is based on the precise linear model of controlled system, ADRFC is more applicable to nonlinear system with time-variant parameters or incomplete model structure. From this point of view, ADRFC reduces the requirement on model accuracy in the premise of ensuring control performance. The obvious advantage of ADRFC lies in its robustness. But PID is only applicable to a certain stable condition and requires a combination of adaptive strategy to improve its robustness.

In the design of ADRFC, ESO (Extended State Observer) is used for estimation of system unmodeled dynamics and unknown wave disturbance, which are controlled effectively through compensation method [5]. If AUV motion model is 


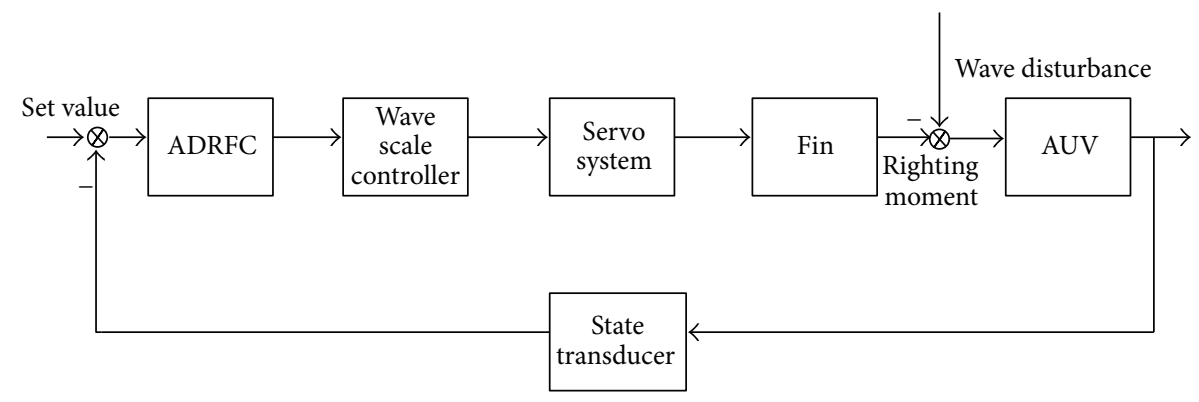

FIGURE 1: AUV stabilizing system schematic diagram.

not accurate and sea conditions are varying constantly, the method is very fit for designing AUV roll stabilizing control. Because AUV roll motion state estimated by ESO is required for nonlinear feedback control, gains of state feedback are obtained through fuzzy reasoning method. Then, control law for the closed loop system is designed and self-adjustment of control parameters is realized online. Reference [2] discussed how lift force generated by zero-speed fin stabilizer based on Weis-Fogh device changes with $\alpha$ (angle between the two wings of fin) in nonperfect fluid. From lift force model in [2], it is easily found that lift force not only has relations to $\alpha$, but also varies with $\omega$ (angular rate of fin wings flapping) and $\dot{\omega}$ (angular acceleration of fin wings flapping). In order to realize lift force control accurately and effectively, a secondorder Riccati differential equation about $\dot{\omega}$ is required to be solved in nature. But, the differential equation is very complicated and hard to solve in analytical mathematics. Thus, approximate linearization method is used in this paper to calculate lift force; namely, the hypothesis is made that $\dot{\omega}$ is varying while $\omega$ and $\alpha$ keep invariant in a very small sampling time interval $[k, k+1], \omega$ is calculated by integrating $\dot{\omega}$ in $[k, k+1]$ when sampling time is $k+1$, and similarly $\alpha$ is calculated by integrating $\omega$ in $[k, k+1]$. In approximate linearization method, $\alpha$ control is replaced by $\dot{\omega}$ control. As a result, lift force calculation becomes more accurate, and design of lift force control is simplified.

\section{Roll Stabilizing Principle of AUV with Low Speed}

Schematic diagram of AUV roll stabilizing system is shown in Figure 1.

Motion attitude of AUV with low speed is controlled through actuation of system controller. Wings of fin stabilizer actively flap around the fin axis with high frequency in sea water. Lift on the wing surface is generated under driving of servo system. Lift righting moment counteracts wave moment effectively, and then roll motion amplitude is reduced [6]. Relevant parameters of fin stabilizer are shown as follows: span length is $0.25 \mathrm{~m}$, chord length is $0.5 \mathrm{~m}$, and AUV navigating speed is $1.832 \mathrm{~m} / \mathrm{s}$. According to traditional roll stabilizing theory, lift force is calculated from

$$
L_{\text {lift }}=\frac{1}{2} \rho A_{f} C_{L} u^{2},
$$

where $\rho$ is sea water density, $A_{f}$ is projected area of fin, $C_{L}$ is coefficient of lift force, and $u$ is AUV navigating speed. Lift values calculated from (1) are very small and several Newton in quantity if fin size and navigating speed are set as parameters mentioned above. Lift of fin is too small to satisfy the need of roll stabilizing. But zero-speed fin stabilizer, which has the same size and is based on Weis-Fogh device, can generate enough lift force to counteract wave disturbance in the case of low speed navigation near water surface. Thus, lift model of zero-speed fin stabilizer based on Weis-Fogh device is adopted in the following discussion.

Considering special working pattern of zero-speed fin stabilizer, force analysis during normal working of fin commits to category of unsteady flow problem [7]. When zerospeed fin stabilizer flaps in perfect or nonperfect fluid, lift generated on the fin can be analyzed by using potential theory and vortex action theory instead of fix wing theory [8]. Through relevant deduction, lift model of zero-speed fin stabilizer can be described as

$$
\begin{aligned}
L_{\text {zero }} & =\left[\frac{e \rho}{3}\left(C_{d}+3 k\right)\left(3 a^{2} c+c^{3}\right) \omega^{2}+\frac{J}{d} \dot{\omega}\right] \cos (\omega t) \\
& =\left(a_{1} \omega^{2}+a_{2} \dot{\omega}\right) \cos (\omega t) .
\end{aligned}
$$

In (2), $e$ is span length, $\rho$ is sea water density, $C_{d}$ is coefficient of drag force, $k$ is proportion factor, $2 a$ is chord length, $c$ is distance from fin axis to midpoint of chord length, $\omega$ is angular rate of fin wings flapping, $J$ is additional moment of inertia, $d$ is distance from fin axis to the point where force on additional mass acts, and $a_{1}$ and $a_{2}$ are both constants.

Because the problem discussed in this paper is attitude control of AUV with low navigating speed, it is necessary to consider additional effect of water flow on lift force while sea water flows through fin surface with relative flow speed. The additional lift is in relation to navigating speed, and it is timevariant; namely, additional lift can be denoted as $\Delta L_{\text {lift }}(u, t)$. Thus, lift model of fin stabilizer when AUV is navigating with low speed can be given by

$$
L_{\text {lift }}=L_{\text {zero }}+\Delta L_{\text {lift }}(u, t) .
$$

If navigating speed is $1.832 \mathrm{~m} / \mathrm{s}$, the value of $\Delta L_{\text {lift }}(u, t)$ is much less than that of $L_{\text {zero }}$. Ratio of additional lift to total lift is $3 \%-4 \%$. So, (4) can be approximately accepted in simulations:

$$
L_{\text {lift }} \approx L_{\text {zero }}
$$




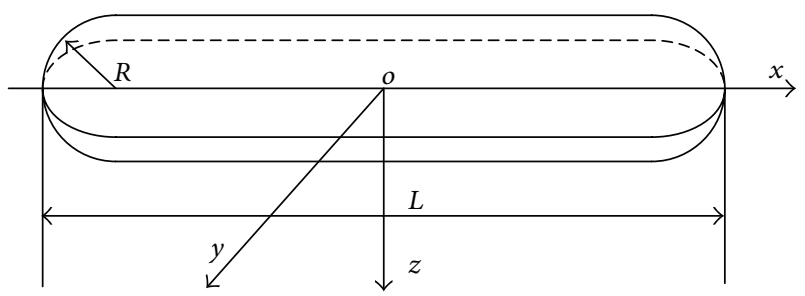

FIgURE 2: Simplified AUV figure.

\section{Calculation of Wave Moment Near Water Surface}

Practical AUV figure can be simplified and approximately described as combination object composed of a cylinder in the middle and two half spheres on both symmetrical sides as shown in Figure 2.

AUV figure is expressed as the following mathematical equations:

$$
\begin{gathered}
\left(x+\frac{L}{2}-R\right)^{2}+y^{2}+z^{2}=R^{2} \quad\left(-\frac{L}{2} \leq x \leq-\frac{L}{2}+R\right), \\
y^{2}+z^{2}=R^{2} \quad\left(-\frac{L}{2}+R \leq x \leq \frac{L}{2}-R\right), \\
\left(x-\frac{L}{2}+R\right)^{2}+y^{2}+z^{2}=R^{2} \quad\left(\frac{L}{2}-R \leq x \leq \frac{L}{2}\right),
\end{gathered}
$$

where AUV total length $L$ is $5.3 \mathrm{~m}$, half sphere radius $R$ is $0.5 \mathrm{~m}$, and $(x, y, z)$ is coordinate of a random point on AUV surface. Through analysis of force which is acted on AUV, wave moment encountered when AUV is navigating near water surface can be calculated. Because velocity and acceleration at each point on AUV surface are different and sea water passes by each point on AUV surface with different velocity and acceleration, wave moment near water surface can be calculated through integration method. From (5), coordinate distance between $(x, y, z)$ and $\left(x^{\prime}, y^{\prime}, z^{\prime}\right)$, which are two random points on AUV surface, can be expressed as

$$
\begin{gathered}
\left(x-x^{\prime}\right)= \begin{cases}2 \sqrt{\frac{1}{4}-y^{2}-z^{2}}-4.3 & (-0.5 \leq y \leq 0) \\
2 \sqrt{\frac{1}{4}-y^{2}-z^{2}}+4.3 & (0 \leq y \leq 0.5)\end{cases} \\
\left(y-y^{\prime}\right)= \begin{cases}2 \sqrt{\frac{1}{4}-z^{2}-(x+2.15)^{2}} & (-2.65 \leq x \leq-2.15) \\
2 \sqrt{\frac{1}{4}-z^{2}} & (-2.15 \leq x \leq 2.15) \\
2 \sqrt{\frac{1}{4}-z^{2}-(x-2.15)^{2}} & (2.15 \leq x \leq 2.65),\end{cases}
\end{gathered}
$$

$$
\left(z-z^{\prime}\right)= \begin{cases}2 \sqrt{\frac{1}{4}-y^{2}-(x+2.15)^{2}} & (-2.65 \leq x \leq-2.15) \\ 2 \sqrt{\frac{1}{4}-y^{2}} & (-2.15 \leq x \leq 2.15) \\ 2 \sqrt{\frac{1}{4}-y^{2}-(x-2.15)^{2}} & (2.15 \leq x \leq 2.65)\end{cases}
$$

because model of long crested wave can be expressed as

$$
\zeta=\sum_{i=1}^{n} \zeta_{i} \cos \left(\omega_{i} t+\varepsilon_{i}\right),
$$

where $\zeta$ is wave amplitude, $\omega_{i}$ is wave frequency, and wave phase $\varepsilon_{i}$ is a random variable subject to uniform distribution in $0 \sim 2 \pi$. Velocity and acceleration of wave at the point $(x, y, z)$ can be obtained and given by

$$
\begin{aligned}
& V_{W}=\frac{d \zeta_{W}}{d t}=-\omega_{i} \sum_{i=1}^{n} e^{-h_{B} k_{i}} \zeta_{i} \sin \left(\omega_{i} t+\varepsilon_{i}\right), \\
& a_{W}=\frac{d V_{W}}{d t}=-\omega_{i}^{2} \sum_{i=1}^{n} e^{-h_{B} k_{i}} \zeta_{i} \cos \left(\omega_{i} t+\varepsilon_{i}\right) .
\end{aligned}
$$

In (8), $h_{B}$ is depth from the center of water particle motion trajectory to water surface, and $k_{i}$ is wave number. Thus, wave moment is expressed as

$$
\begin{aligned}
& M_{\text {wave }} \\
& =\iint\left[C_{d} \rho \frac{\left(V_{W}-V\right)^{2}}{2}+k^{\prime}\left(a_{W}-a\right) \rho\left(z-z^{\prime}\right)\right] y d x d y,
\end{aligned}
$$

where $C_{d}$ is coefficient of drag force, $\rho$ is sea water density, and $k^{\prime}$ is coefficient of additional mass. $k^{\prime}$ is 1.0 for cylinder moving towards water flow, and 0.5 for sphere. $V$ and $a$ are vertical velocity and acceleration at the point $(x, y, z)$, respectively. Equation (9) is expanded, and then expression for numerical calculation of wave moment is given by

$$
\begin{aligned}
M_{\text {wave }}=\iint\left\{C_{d} \rho \frac{\left[-\omega_{i} \sum_{i=1}^{n} e^{-h_{B} k_{i}} \zeta_{i} \sin \left(\omega_{i} t+\varepsilon_{i}\right)-V\right]^{2}}{2}\right. \\
+\left[-\omega_{i}^{2} \sum_{i=1}^{n} e^{-h_{B} k_{i}} \zeta_{i} \cos \left(\omega_{i} t+\varepsilon_{i}\right)-a\right] \\
\left.\cdot \rho\left(z-z^{\prime}\right)\right\} y d x d y .
\end{aligned}
$$

\section{ADRFC Design}

4.1. AUV Roll Motion Model. Coupling horizontal motion model discussed in this paper is obtained by neglecting 
relevant parameters of AUV vertical motion (heave and pitch) and introducing the term of wave moment into roll motion equation. AUV coupling horizontal motion model is expressed as

$$
\begin{aligned}
& {\left[\begin{array}{lll}
a_{11} & a_{12} & a_{13} \\
a_{21} & a_{22} & a_{23} \\
a_{31} & a_{32} & a_{33}
\end{array}\right] \cdot\left[\begin{array}{c}
\dot{v} \\
\dot{p} \\
\dot{r}
\end{array}\right]} \\
& =u \cdot\left[\begin{array}{lll}
b_{11} & b_{12} & b_{13} \\
b_{21} & b_{22} & b_{23} \\
b_{31} & b_{32} & b_{33}
\end{array}\right] \cdot\left[\begin{array}{l}
v \\
p \\
r
\end{array}\right]+\left[\begin{array}{c}
0 \\
f+M_{\text {wave }}+M_{\text {fin }} \\
0
\end{array}\right],
\end{aligned}
$$

where $a_{11}=m-(1 / 2) \rho L^{3} Y_{\dot{v}}^{\prime}, a_{12}=-\left(m z_{G}+(1 / 2) \rho L^{4} Y_{\dot{p}}^{\prime}\right)$, $a_{13}=-(1 / 2) \rho L^{4} Y_{\dot{r}}^{\prime}, a_{21}=m z_{G}-(1 / 2) \rho L^{4} K_{\dot{v}}^{\prime}, a_{22}=I_{x}-$ $(1 / 2) \rho L^{5} K_{\dot{p}}^{\prime}, a_{23}=-(1 / 2) \rho L^{5} K_{\dot{r}}^{\prime}, a_{31}=-(1 / 2) \rho L^{4} N_{\dot{v}}^{\prime}, a_{32}=$ $-\left(I_{x z}+(1 / 2) \rho L^{5} N_{\dot{p}}^{\prime}\right), a_{33}=I_{z}-(1 / 2) \rho L^{5} N_{\dot{r}}^{\prime}, b_{11}=(1 / 2) \rho L^{2} Y_{v}^{\prime}$, $b_{12}=(1 / 2) \rho L^{3} Y_{p}^{\prime}, b_{13}=(1 / 2) \rho L^{3} Y_{r}^{\prime}-m, b_{21}=(1 / 2) \rho L^{3} K_{v}^{\prime}$, $b_{22}=(1 / 2) \rho L^{4}\left(K_{p}^{\prime}+K_{p n}^{\prime} \varepsilon(n)\right), b_{23}=(1 / 2) \rho L^{4} K_{r}^{\prime}-m z_{G}, b_{31}=$ $(1 / 2) \rho L^{3} N_{v}^{\prime}, b_{32}=(1 / 2) \rho L^{4} N_{p}^{\prime}, b_{33}=(1 / 2) \rho L^{4} N_{r}^{\prime}, f=$ $-z_{G} W \phi . v, p$, and $r$ are sway velocity, roll angular rate, and yaw angular rate, respectively. $u$ is navigating speed, $M_{\text {wave }}$ is wave moment, and $M_{\text {fin }}$ is righting moment generated by zero-speed fin stabilizer; namely,

$$
M_{\text {fin }}=2 L_{\text {lift }} \cdot l_{f}=2 l_{f}\left(a_{1} \omega^{2}+a_{2} \dot{\omega}\right) \cos (\omega t),
$$

where $l_{f}$ is lever of righting moment. Meanings for other symbols in (11) can be found in [9]. Equation (11) is simplified into the following matrix equation:

$$
\begin{aligned}
{\left[\begin{array}{l}
\ddot{D} \\
\ddot{\phi} \\
\ddot{\psi}
\end{array}\right]=} & \cdot\left[\begin{array}{lll}
a_{11} & a_{12} & a_{13} \\
a_{21} & a_{22} & a_{23} \\
a_{31} & a_{32} & a_{33}
\end{array}\right]^{-1} \\
& \cdot\left[\begin{array}{lll}
b_{11} & b_{12} & b_{13} \\
b_{21} & b_{22} & b_{23} \\
b_{31} & b_{32} & b_{33}
\end{array}\right] \cdot\left[\begin{array}{c}
\dot{D} \\
\dot{\phi} \\
\dot{\psi}
\end{array}\right]+\left[\begin{array}{lll}
a_{11} & a_{12} & a_{13} \\
a_{21} & a_{22} & a_{23} \\
a_{31} & a_{32} & a_{33}
\end{array}\right]^{-1} \\
& \cdot\left[\begin{array}{c}
0 \\
f+M_{\text {wave }}+M_{\text {fin }} \\
0
\end{array}\right]
\end{aligned}
$$

$$
\begin{gathered}
=u \cdot\left[\begin{array}{lll}
c_{11} & c_{12} & c_{13} \\
c_{21} & c_{22} & c_{23} \\
c_{31} & c_{32} & c_{33}
\end{array}\right] \cdot\left[\begin{array}{c}
\dot{D} \\
\dot{\phi} \\
\dot{\psi}
\end{array}\right] \\
+\left[\begin{array}{lll}
d_{11} & d_{12} & d_{13} \\
d_{21} & d_{22} & d_{23} \\
d_{31} & d_{32} & d_{33}
\end{array}\right] \cdot\left[\begin{array}{c}
0 \\
f+M_{\mathrm{wave}}+M_{\mathrm{fin}} \\
0
\end{array}\right] .
\end{gathered}
$$

In (13), $D, \phi$, and $\psi$ are sway displacement, roll angle, and yaw angle, respectively. Equation (13) can be further simplified into (14) through linearization and Laplace transformation:

$$
\begin{aligned}
{\left[\begin{array}{l}
D(s) \\
\phi(s) \\
\psi(s)
\end{array}\right]=} & {\left[\begin{array}{lll}
e_{11} & e_{12} & e_{13} \\
e_{21} & e_{22} & e_{23} \\
e_{31} & e_{32} & e_{33}
\end{array}\right]^{-1} \cdot\left[\begin{array}{lll}
d_{11} & d_{12} & d_{13} \\
d_{21} & d_{22} & d_{23} \\
d_{31} & d_{32} & d_{33}
\end{array}\right] } \\
& \cdot\left[\begin{array}{c}
0 \\
M_{\text {fin }} \\
0
\end{array}\right]+\left[\begin{array}{lll}
e_{11} & e_{12} & e_{13} \\
e_{21} & e_{22} & e_{23} \\
e_{31} & e_{32} & e_{33}
\end{array}\right] \\
& \cdot\left[\begin{array}{ccc}
d_{11} & d_{12} & d_{13} \\
d_{21} & d_{22} & d_{23} \\
d_{31} & d_{32} & d_{33}
\end{array}\right] \cdot\left[\begin{array}{c}
0 \\
M_{\text {wave }} \\
0
\end{array}\right] \\
= & {\left[\begin{array}{lll}
f_{11} & f_{12} & f_{13} \\
f_{21} & f_{22} & f_{23} \\
f_{31} & f_{32} & f_{33}
\end{array}\right] \cdot\left[\begin{array}{c}
0 \\
M_{\text {fin }} \\
0
\end{array}\right] } \\
& +\left[\begin{array}{lll}
f_{11} & f_{12} & f_{13} \\
f_{21} & f_{22} & f_{23} \\
f_{31} & f_{32} & f_{33}
\end{array}\right] \cdot\left[\begin{array}{c}
0 \\
M_{\text {wave }} \\
0
\end{array}\right]
\end{aligned}
$$

where $e_{11}=s^{2}-c_{11} u \cdot s, e_{12}=-c_{12} u \cdot s-d_{12} \cdot(\partial f / \partial \phi), e_{13}=$ $-c_{13} u \cdot s, e_{21}=-c_{21} u \cdot s, e_{22}=s^{2}-c_{22} u \cdot s-d_{22} \cdot(\partial f / \partial \phi)$, $e_{23}=-c_{23} u \cdot s, e_{31}=-c_{31} u \cdot s, e_{32}=-c_{32} u \cdot s-d_{32} \cdot(\partial f / \partial \phi)$, $e_{33}=s^{2}-c_{33} u \cdot s$. From (14), equivalent decoupling model of AUV roll motion can be described as

$$
\phi(s)=f_{22}\left(M_{\text {fin }}+M_{\text {wave }}\right) .
$$

Corresponding AUV hydrodynamic parameters in [10] are substituted into (11) and expression for $f_{22}$ is obtained through derivation of (13) and (14):

$$
f_{22}=\frac{0.0002416 s^{2}+0.0002044 s+0.00002912}{s^{4}+2.7629 s^{3}+2.518 s^{2}+0.8899 s+0.095} .
$$

Higher-order model in (16) can be reduced into an equivalent second-order roll motion model given by

$$
f_{22}=\frac{0.00016347}{s^{2}+1.2928 s+0.6058} .
$$




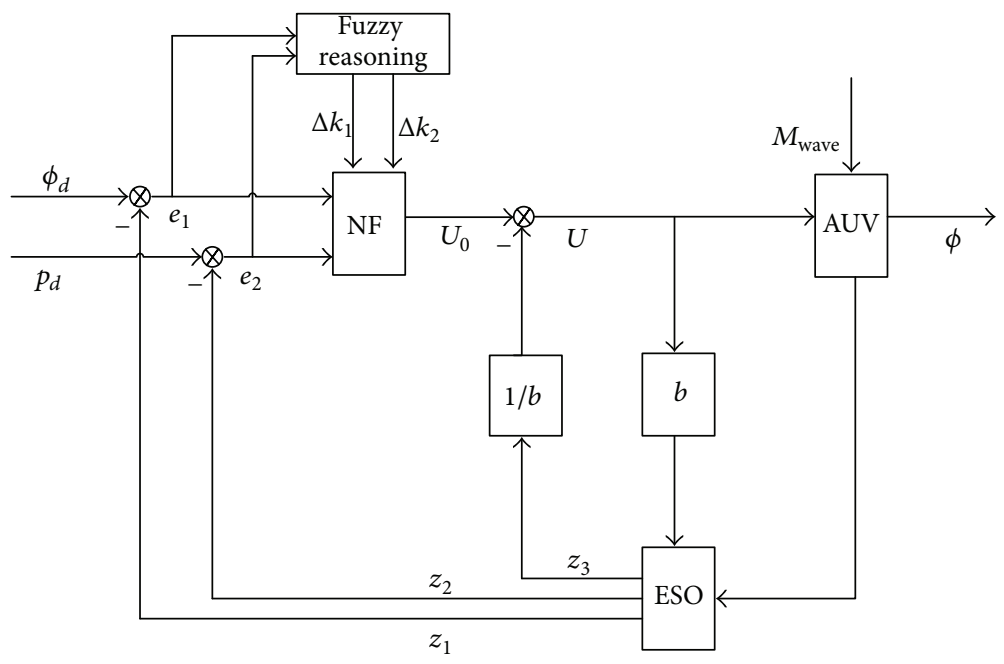

FIgURE 3: Schematic diagram of AUV ADRFC system.

Considering the initial condition, namely, $\phi^{(1)}(0)=\phi(0)=0$, (17) is substituted into (15), and then roll motion model can be expressed as a second-order differential equation through inverse Laplace transformation:

$$
\begin{aligned}
& \phi^{(2)}(t)+1.2928 \phi^{(1)}(t)+0.6058 \phi(t) \\
& \quad=0.00016347 M_{\text {fin }}(t)+0.00016347 M_{\text {wave }}(t) .
\end{aligned}
$$

4.2. Design of $A U V$ ADRFC System. ADRFC is generally composed of ESO and NF (nonlinear feedback). Schematic diagram of AUV ADRFC system is shown in Figure 3.

In Figure $3, \phi_{d}$ and $p_{d}$ are set values of roll angle and roll angular rate, respectively. ESO outputs, namely, $z_{1}, z_{2}$, and $z_{3}$ are estimated values of $\phi, p$, and $M_{\text {wave }}$, respectively. $e_{1}$ is error of the desired variable and the real variable for roll angle. $e_{2}$ is error of the desired variable and the real variable for roll angular rate. $k_{1}$ and $k_{2}$ are coefficients of NF. $U$ is control input and $b$ is coefficient of control input. $U_{0}$ is control input when wave moment is not compensated.

4.2.1. ESO Design. ESO is mainly used for estimating state and disturbance. Convergence and estimation error of ESO can be analyzed by applying SSR (Self Stable Region) theory and piecewise smooth Lyapunov function [11-16]. Here, basic principle of ESO is not stated in detail. ESO theory is directly applied for design of roll motion state observer. Equation (12) is substituted into (18), and then (19) is obtained through further simplification:

$$
\dot{p}=f+b \dot{\omega} .
$$

In (19),

$$
\begin{gathered}
b=0.00016347 \cdot 2 l_{f} a_{2} \cos (\omega t), \\
f=-1.2928 p-0.6058 \phi+0.00016347 M_{\text {wave }} \\
+0.00016347 \cdot 2 l_{f} a_{1} \omega^{2} \cos (\omega t) .
\end{gathered}
$$

If control input $U$ is set as $\dot{\omega}$, namely, $U=\dot{\omega}$, and state variables $x_{1}, x_{2}$, and $x_{3}$ are set as $x_{1}=\phi, x_{2}=p, x_{3}=f$, ESO can be designed and expressed as

$$
\begin{gathered}
\varepsilon=z_{1}-\phi, \\
\dot{z}_{1}=z_{2}-\beta_{1} \operatorname{fal}\left(\varepsilon, \alpha_{1}, \lambda\right), \\
\dot{z_{2}}=z_{3}-\beta_{2} \operatorname{fal}\left(\varepsilon, \alpha_{2}, \lambda\right)+b U+g, \\
\dot{z_{3}}=-\beta_{3} \operatorname{fal}\left(\varepsilon, \alpha_{3}, \lambda\right),
\end{gathered}
$$

where $\varepsilon$ is estimation error of roll angle, $\beta_{1}, \beta_{2}$, and $\beta_{3}$ are ESO coefficients; expression for $g$ and fal $\left(\varepsilon, \alpha_{i}, \lambda\right)(i=1,2,3)$ are given by

$$
\begin{array}{r}
g=-1.2928 z_{2}-0.6058 z_{1} \\
+0.00016347 \cdot 2 l_{f} a_{1} \omega^{2} \cos (\omega t), \\
\operatorname{fal}\left(\varepsilon, \alpha_{i}, \lambda\right)= \begin{cases}|\varepsilon|^{\alpha_{i}} \operatorname{sgn}(\varepsilon) & |\varepsilon|>\lambda \\
\frac{\varepsilon}{\lambda^{1-\alpha_{i}}} & |\varepsilon| \leq \lambda .\end{cases}
\end{array}
$$

In (26), $\alpha_{i}$ is exponential factor, and $\lambda$ is filter factor. $\alpha_{i}$ and $\lambda$ should satisfy the following relations: $0<\alpha_{i}<1, \lambda>0$.

4.2.2. ESO Coefficient Self-Adjustment. ESO coefficients $\beta_{1}$ and $\beta_{2}$ can be adjusted online by two neurons. ESO estimation error is reduced through self-adjustment of $\beta_{1}$ and $\beta_{2}$. Principle of ESO coefficient self-adjustment with neurons is shown in Figure 4. 


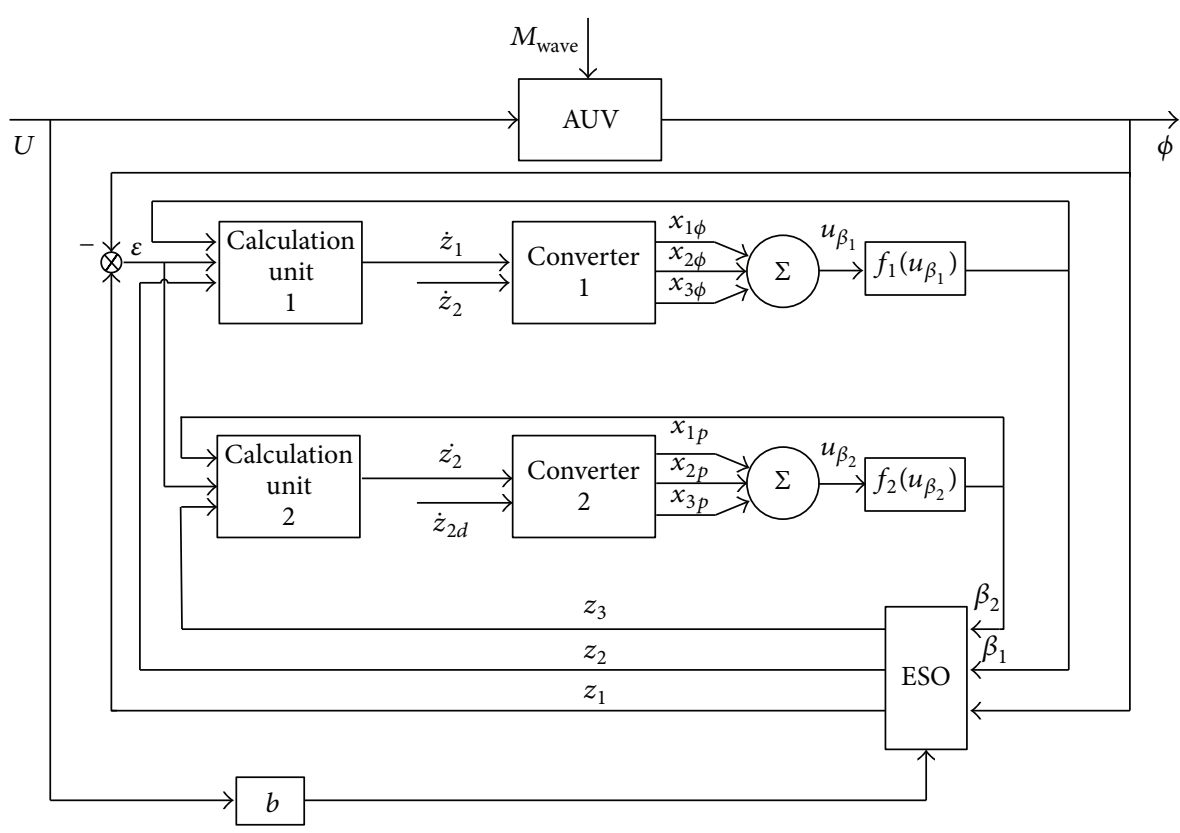

FIGURE 4: ESO coefficient self-adjustment with neurons.

In Figure 4, upper neuron and lower neuron are used for adjustment of $\beta_{1}$ and $\beta_{2}$, respectively. Adopted control algorithm is expressed as

$$
\begin{gathered}
\beta_{1}(k+1)=k_{1}^{\prime} \sum_{i=1}^{3} \omega_{i \phi}^{\prime}(k) x_{i \phi}(k), \\
\omega_{i \phi}^{\prime}(k)=\frac{\omega_{i \phi}(k)}{\sum_{i=1}^{3}\left|\omega_{i \phi}(k)\right|}, \\
\omega_{i \phi}(k+1)=\omega_{i \phi}(k)+d_{1} e_{3}(k) \dot{z}_{1}(k) x_{i \phi}(k) .
\end{gathered}
$$

In (27), $k$ is current time, learning speed $d_{1}>0, \omega_{i \phi}(k)$ is upper neuron weight, and $k_{1}^{\prime}$ is coefficient of upper neuron gain. If $e_{3}(k)=z_{1 d}-\dot{z}_{1}(k)$, upper neuron input is given by

$$
\begin{gathered}
x_{1 \phi}(k)=e_{3}(k), \\
x_{2 \phi}(k)=e_{3}(k)-e_{3}(k-1), \\
x_{3 \phi}(k)=e_{3}(k)-2 e_{3}(k-1)+e_{3}(k-2),
\end{gathered}
$$

where set value $z_{1 d}=0$, and $\dot{z}_{1}(k)$ is roll angular rate estimated by ESO. Similarly, control algorithm of lower neuron is expressed as

$$
\begin{gathered}
\beta_{2}(k+1)=\frac{k_{2}^{\prime} \sum_{i=1}^{3} \omega_{i p}(k) x_{i p}(k)}{\sum_{i=1}^{3}\left|\omega_{i p}(k)\right|}, \\
\omega_{i p}(k+1)=\omega_{i p}(k)+d_{2} e_{4}(k) \dot{z}_{2}(k) x_{i p}(k) .
\end{gathered}
$$

If $e_{4}(k)=z_{2 d}^{\dot{z}}-\dot{z_{2}}(k)$, lower neuron input is given by

$$
\begin{gathered}
x_{1 p}(k)=e_{4}(k), \\
x_{2 p}(k)=e_{4}(k)-e_{4}(k-1), \\
x_{3 p}(k)=e_{4}(k)-2 e_{4}(k-1)+e_{4}(k-2) .
\end{gathered}
$$

Set value $z_{2 d}=0, \dot{z_{2}}(k)$ is roll angular acceleration estimated by ESO, learning speed $d_{2}>0, \omega_{i p}(k)$ is lower neuron weight, and $k_{2}^{\prime}$ is coefficient of lower neuron gain. Calculation unit 1 and calculation unit 2 in Figure 4 can be described as (22) and (23). Thus, algorithm of ESO coefficient self-adjustment with neurons is composed of (21)-(23) and (27)-(30).

4.2.3. NF Design. In Figure 3, NF is used for constituting control law. NF algorithm can be expressed as

$$
\begin{gathered}
e_{1}=\phi_{d}-z_{1}=-z_{1}, \\
e_{2}=p_{d}-z_{2}=-z_{2}, \\
U_{0}=k_{1} \mathrm{fal}\left(e_{1}, \alpha_{4}, \lambda_{1}\right)+k_{2} \mathrm{fal}\left(e_{2}, \alpha_{5}, \lambda_{2}\right), \\
U=U_{0}-\frac{\left(z_{3}+g\right)}{b} .
\end{gathered}
$$

In (33), $\alpha_{4}$ and $\alpha_{5}$ are exponential factors and $\lambda_{1}$ and $\lambda_{2}$ are filter factors. Compensation term in (34), namely, $\left(z_{3}+g\right) / b$, embodies the nature of ADRFC. When the system is affected by unknown wave disturbance, controller simultaneously gives estimation and compensation. Equation (34) is expression for angular acceleration calculation of fin stabilizer wings flapping; namely, control input $U$ can be 
TABLE 1: Statistics of roll stabilizing performance.

\begin{tabular}{|c|c|c|c|c|}
\hline $\begin{array}{l}\text { Significant } \\
\text { wave height } \\
\text { (m) }\end{array}$ & $\begin{array}{l}\text { Wave encounter } \\
\text { angle } \\
\left(^{\circ}\right)\end{array}$ & $\begin{array}{l}\text { Standard deviation of roll angle } \\
\text { without roll control } \\
\left(^{\circ}\right)\end{array}$ & $\begin{array}{l}\text { Standard deviation of roll } \\
\text { angle with ADRFC } \\
\left(^{\circ}\right)\end{array}$ & $\begin{array}{c}\text { Roll stabilizing } \\
\text { performance } \\
(\%)\end{array}$ \\
\hline$H_{s}=1$ & $\gamma=45^{\circ}$ & 2.7303 & 1.5257 & 68.77 \\
\hline$H_{s}=1$ & $\gamma=90^{\circ}$ & 3.1697 & 1.6830 & 71.81 \\
\hline$H_{s}=1$ & $\gamma=135^{\circ}$ & 1.8709 & 1.0373 & 69.26 \\
\hline$H_{s}=1.2$ & $\gamma=45^{\circ}$ & 3.3195 & 1.8280 & 69.67 \\
\hline$H_{s}=1.2$ & $\gamma=90^{\circ}$ & 3.7854 & 2.0477 & 70.74 \\
\hline$H_{s}=1.2$ & $\gamma=135^{\circ}$ & 2.2526 & 1.2185 & 70.73 \\
\hline$H_{s}=1.5$ & $\gamma=45^{\circ}$ & 3.8762 & 2.1797 & 68.38 \\
\hline$H_{s}=1.5$ & $\gamma=90^{\circ}$ & 4.6059 & 2.5609 & 69.09 \\
\hline$H_{s}=1.5$ & $\gamma=135^{\circ}$ & 2.7464 & 1.5309 & 68.93 \\
\hline
\end{tabular}

calculated from (34). According to approximate linearization method in small time interval, $\omega$ and $\alpha$ are given by

$$
\begin{gathered}
\omega_{k}=\omega_{k-1}+\dot{\omega}_{k-1} \cdot T=\omega_{k-1}+U_{k-1} \cdot T, \\
\alpha_{k}=\alpha_{k-1}+\omega_{k} \cdot T .
\end{gathered}
$$

Considering fin stabilizer wings flapping with high frequency, sample time $T$ is set as $1 \mathrm{~ms}$; namely, $T=1 \mathrm{~ms}$. Equations (31)-(35) constitute control law of ADRFC for roll stabilizing.

4.2.4. Fuzzy Reasoning Design. In Figure 3, $e_{1}$ (error of roll angle) and $e_{2}$ (error of roll angular rate) are input variables of fuzzy reasoning and $\Delta k_{1}$ and $\Delta k_{2}$ (increment of NF coefficients $k_{1}$ and $k_{2}$ ) are output variables of fuzzy reasoning. Fuzzy subset of linguistic values for $e_{1}$ and $e_{2}$ can be described as \{Negative Big, Negative Middle, Negative Small, Zero, Positive Small, Positive Middle, Positive Big\} and abbreviated as $\{\mathrm{NB}, \mathrm{NM}, \mathrm{NS}, \mathrm{ZO}, \mathrm{PS}, \mathrm{PM}, \mathrm{PB}\} . e_{1}$ and $e_{2}$ are quantized within the interval $(-3,3)$. Similarly, fuzzy subset of $\Delta k_{1}$ and $\Delta k_{2}$ can be described as $\{\mathrm{NB}, \mathrm{NM}, \mathrm{NS}$, $\mathrm{ZO}, \mathrm{PS}, \mathrm{PM}, \mathrm{PB}\} . \Delta k_{1}$ and $\Delta k_{2}$ are quantized within the same interval $(-3,3)$. Discourse domains for $e_{1}$ and $e_{2}$ are both set as $\{-3,-2,-1,0,1,2,3\}$, discourse domain for $\Delta k_{1}$ is $\{-3,-2,-1,0,1,2,3\}$, and discourse domain for $\Delta k_{2}$ is $\{-0.15,-0.1,-0.05,0,0.05,0.1,0.15\}$. After fuzzy control rule tables for $\Delta k_{1}$ and $\Delta k_{2}$ are set up, fuzzy matrix table of NF coefficients can be designed by applying fuzzy synthesis and reasoning according to membership degree table of each fuzzy subset. Then, NF coefficients $k_{1}$ and $k_{2}$ can be calculated from

$$
\begin{aligned}
& k_{1}(i+1)=k_{1}(i)+\Delta k_{1}(i+1), \\
& k_{2}(i+1)=k_{2}(i)+\Delta k_{2}(i+1) .
\end{aligned}
$$

Column number of fuzzy matrix table is 2 . The first column of fuzzy matrix table corresponds to $\Delta k_{1}$, and the second column corresponds to $\Delta k_{2}$. In (36), $i$ is order number of fuzzy matrix row and corresponds to current time.

\section{Simulation Results}

Total length of AUV is $5.3 \mathrm{~m}$, AUV height is $0.5 \mathrm{~m}$, AUV width is $1 \mathrm{~m}$, navigating depth is $10.5 \mathrm{~m}$, and navigating speed is $1.832 \mathrm{~m} / \mathrm{s}$. Set values of roll angle and roll angular rate are both 0 ; namely, $\phi_{d}=p_{d}=0$. Propeller rotational rate is $52.359 \mathrm{rad} / \mathrm{s}$. Relevant parameters of zero-speed fin stabilizer are given as follows: span length is $0.25 \mathrm{~m}$, chord length is $0.5 \mathrm{~m}$, and distance form fin axis to midpoint of chord length is $0.125 \mathrm{~m}$. Exponential factors are given as follows: $\alpha_{1}=0.5$, $\alpha_{2}=\alpha_{4}=\alpha_{5}=0.25, \alpha_{3}=0.125$. Filter factors are given as $\lambda=\lambda_{1}=\lambda_{2}=0.4$. Initial values of $\beta_{1}, \beta_{2}$, and $\beta_{3}$ are set as 15 , 20 , and 30 , respectively. Parameters of the two self-adaptive neurons are given as follows: gain coefficients are both 0.5 , and learning speeds are both 2 ; namely, $k_{1}^{\prime}=k_{2}^{\prime}=0.5$, $d_{1}=d_{2}=2$. Significant wave height and encountering angle are denoted by $H_{s}$ and $\gamma$, respectively.

Statistics of roll stabilizing performances under different sea conditions is shown in Table 1 . Roll stabilizing performance of ADRFC is defined as the following expression:

Roll stabilizing performance $=$ (standard deviation of roll angle without roll control - standard deviation of roll angle with $\mathrm{ADRFC}) /($ standard deviation of roll angle without roll control).

\section{Conclusions}

(1) Simulation results shown in Figures 5-10 demonstrate that ADRFC embodies favorable robustness and satisfactory performance of roll stabilizing when significant wave height is $1 \mathrm{~m}$ and encountering angle varies from $45 \mathrm{deg}$ to $135 \mathrm{deg}$. There is no instability phenomenon in AUV roll motion.

(2) Simulation results when significant wave height is $1.2 \mathrm{~m}$ and encountering angle is $90 \mathrm{deg}$ are given in Figures 11-13. Roll stabilizing performance of PID is shown in Figure 12. Compared to Figure 13, roll stabilizing performance in Figure 12 is not satisfied. The method proposed in this paper is obviously superior to traditional PID. This result proves that PID is only applicable to precise linear 


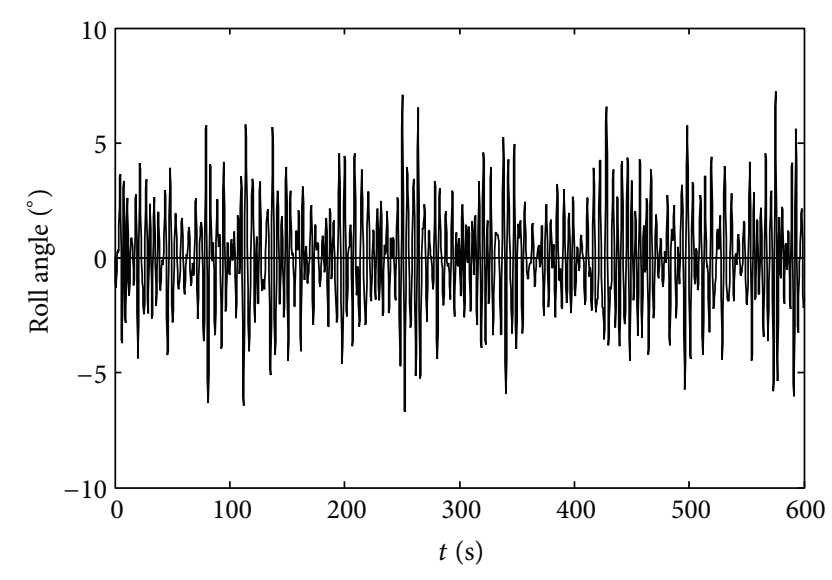

FIGURE 5: Simulation without roll control when $H_{s}=1 \mathrm{~m}$ and $\gamma=$ $45^{\circ}$.

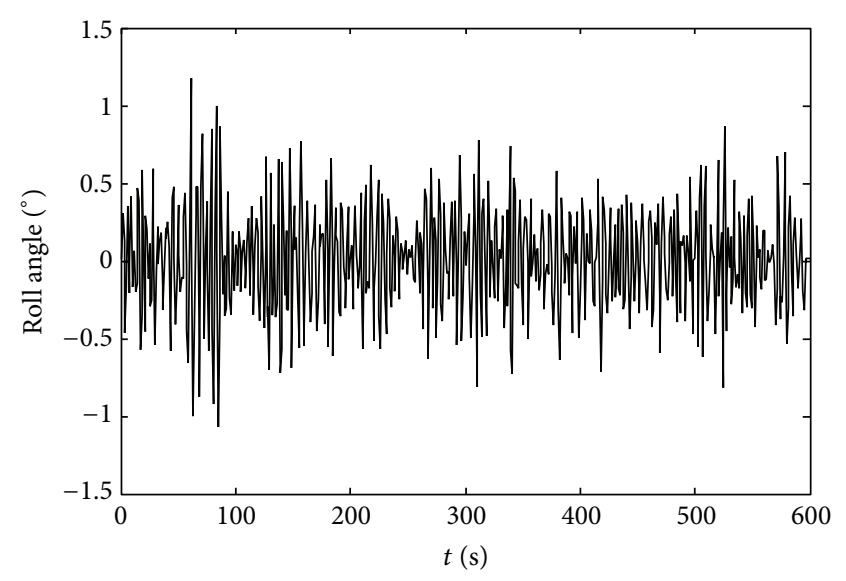

FIGURE 6: Simulation of roll with ADRFC when $H_{s}=1 \mathrm{~m}$ and $\gamma=$ $45^{\circ}$.

model and ADRFC is more applicable to nonlinear system. The same conclusion can be drawn from Figures 14-16 where significant wave height is $1.5 \mathrm{~m}$ and encountering angle is 90 deg.

(3) Fin stabilizer based on Weis-Fogh device is used for roll stabilizing because lift righting moment generated by common fin stabilizer is too small to counteract wave moment when AUV is navigating with low speed. Roll stabilizing performance of fin stabilizer based on Weis-Fogh device is favorable as shown in Table 1.

Because the precise model of AUV roll motion is required in the design of traditional PID, and its robustness is not strong enough for variant sea conditions, roll stabilizing performance of traditional PID which is designed for a certain sea condition deteriorates obviously with sea conditions varying.

Furthermore, AUV will be endangered when violent roll motion appears. In this paper, precise model of AUV roll motion is not required in the design of ADRFC. Some uncertain factors (e.g., wave disturbance) are not necessarily calculated accurately according to sea condition forecast.

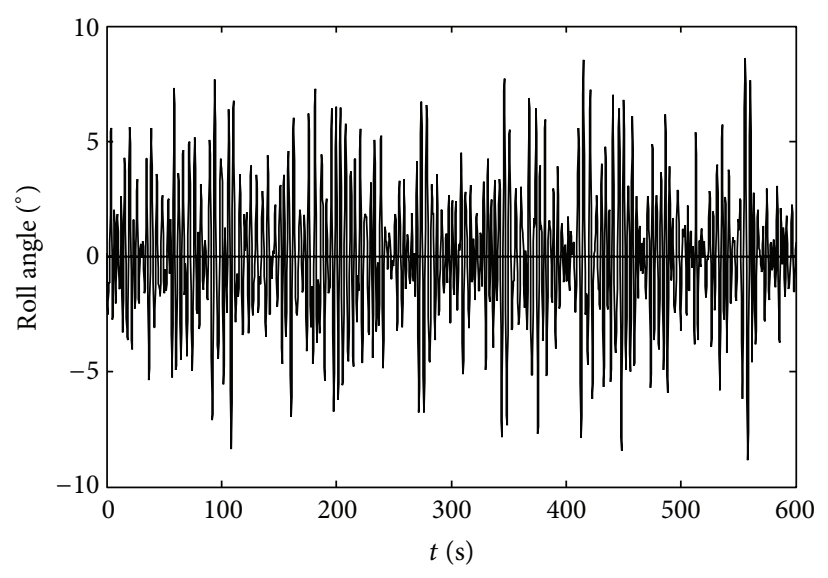

FIGURE 7: Simulation without roll control when $H_{s}=1 \mathrm{~m}$ and $\gamma=$ $90^{\circ}$.

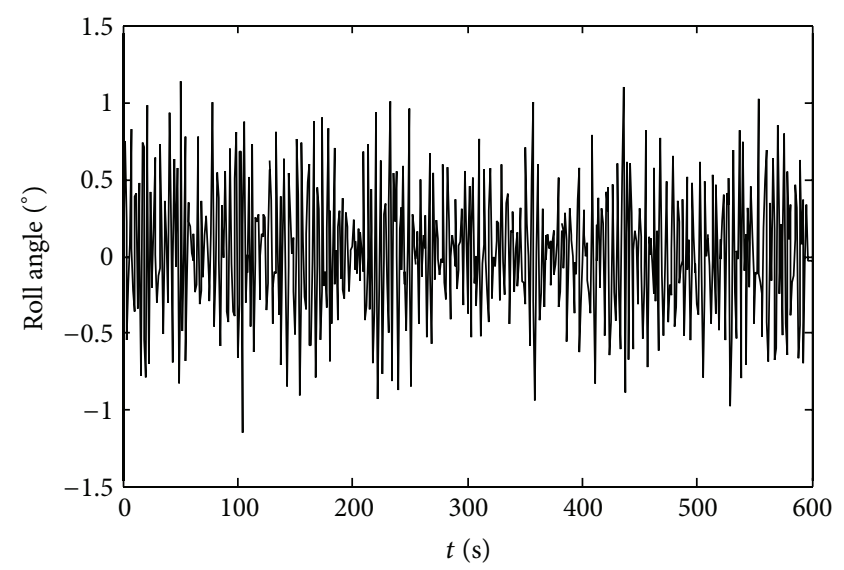

FIGURE 8: Simulation of roll with ADRFC when $H_{s}=1 \mathrm{~m}$ and $\gamma=$ $90^{\circ}$.

The problem of worse robustness for traditional PID is solved through ADRFC based on ESO. AUV roll stabilizing performances under different sea conditions are effectively improved by estimating and compensating unknown wave disturbance.

\section{Conflict of Interests}

The authors declare that there is no conflict of interests regarding the publication of this paper.

\section{Acknowledgment}

Portions of this work were performed under the projects supported by National Natural Science Foundation of China (Grant no. E091002/50979017) and Harbin Science and Technology Innovation Talents of Special Fund Project (Outstanding Subject Leaders) (Grant no. 2012RFXXG083). 


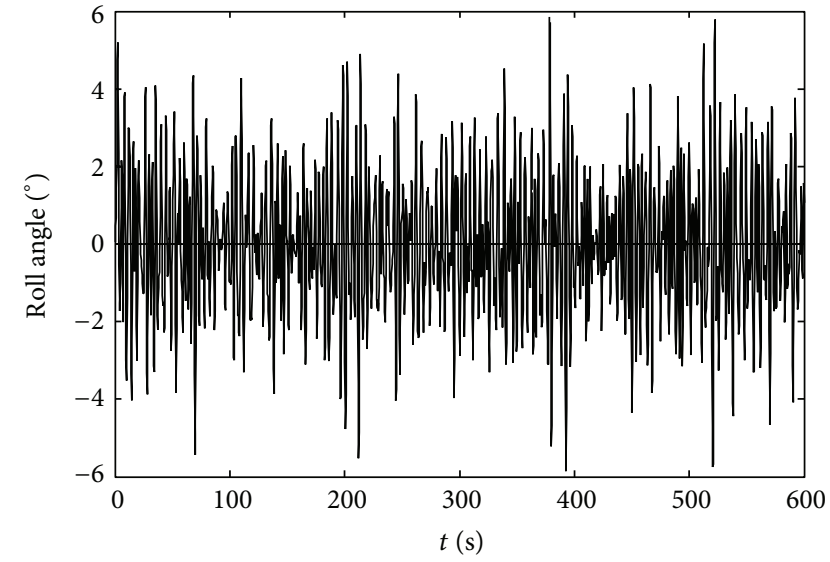

FIGURE 9: Simulation without roll control when $H_{s}=1 \mathrm{~m}$ and $\gamma=$ $135^{\circ}$.

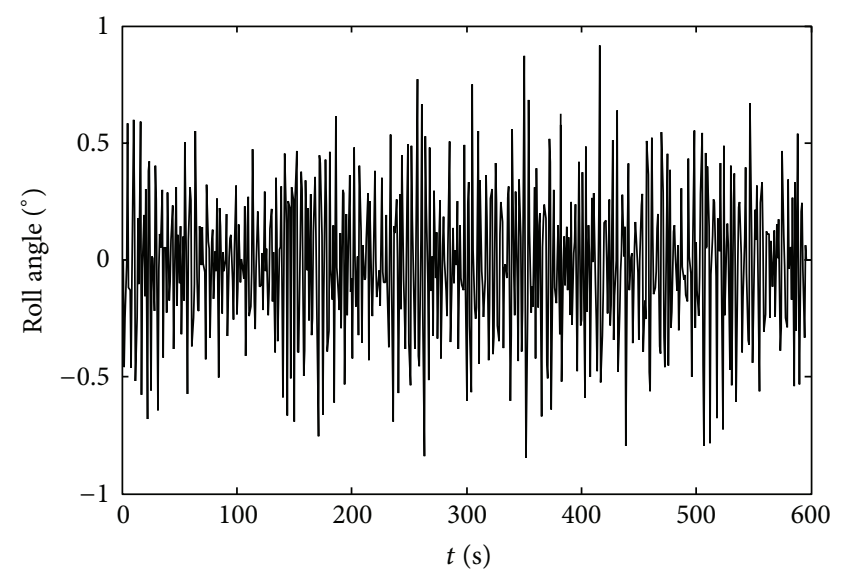

FIGURE 10: Simulation of roll with ADRFC when $H_{s}=1 \mathrm{~m}$ and $\gamma=$ $135^{\circ}$.

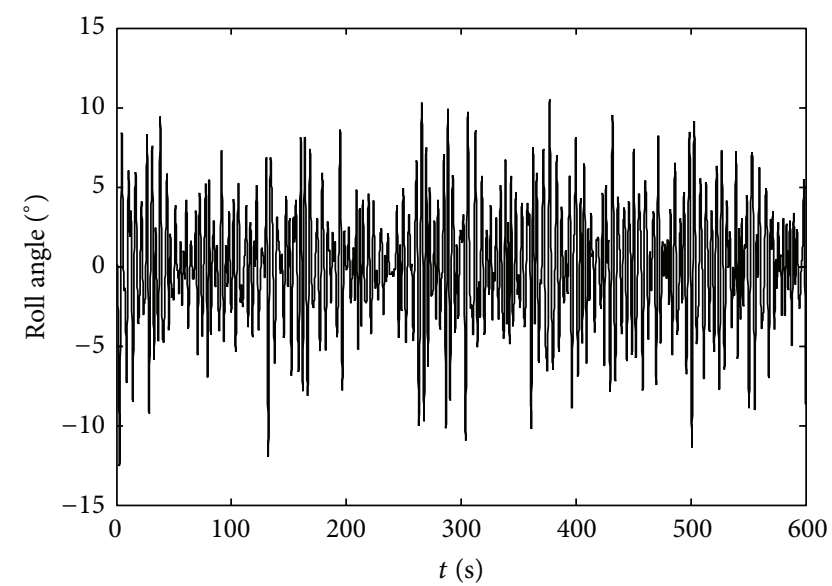

FIgURE 11: Simulation without roll control when $H_{s}=1.2 \mathrm{~m}$ and $\gamma=90^{\circ}$.

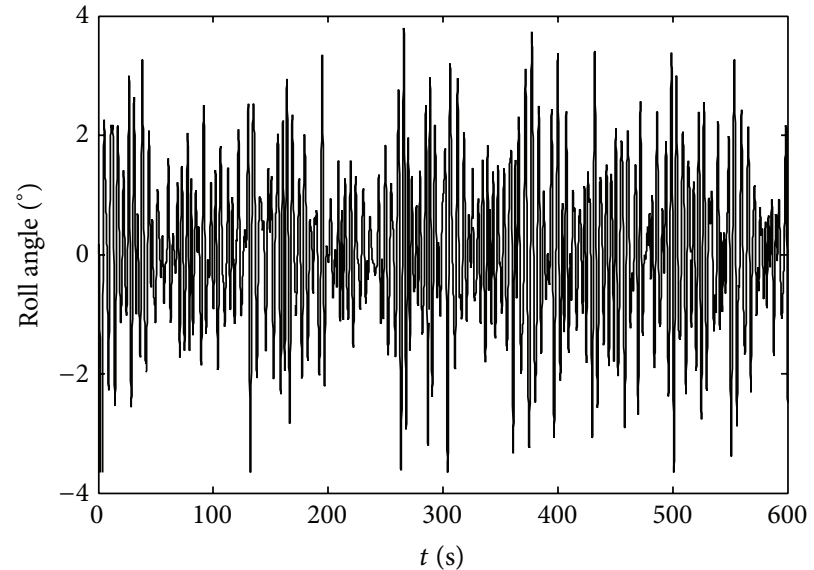

FIGURE 12: Simulation of roll with PID when $H_{s}=1.2 \mathrm{~m}$ and $\gamma=90^{\circ}$.

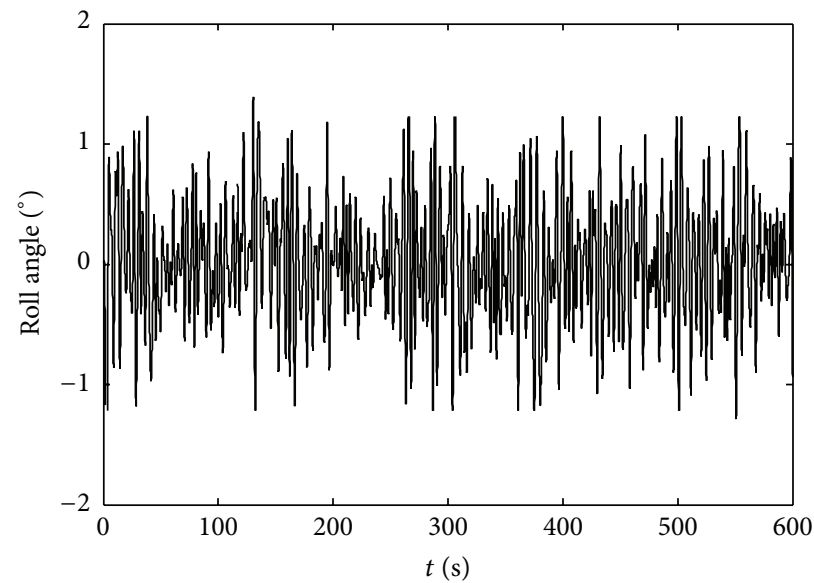

FIgURE 13: Simulation of roll with ADRFC when $H_{s}=1.2 \mathrm{~m}$ and $\gamma=90^{\circ}$.

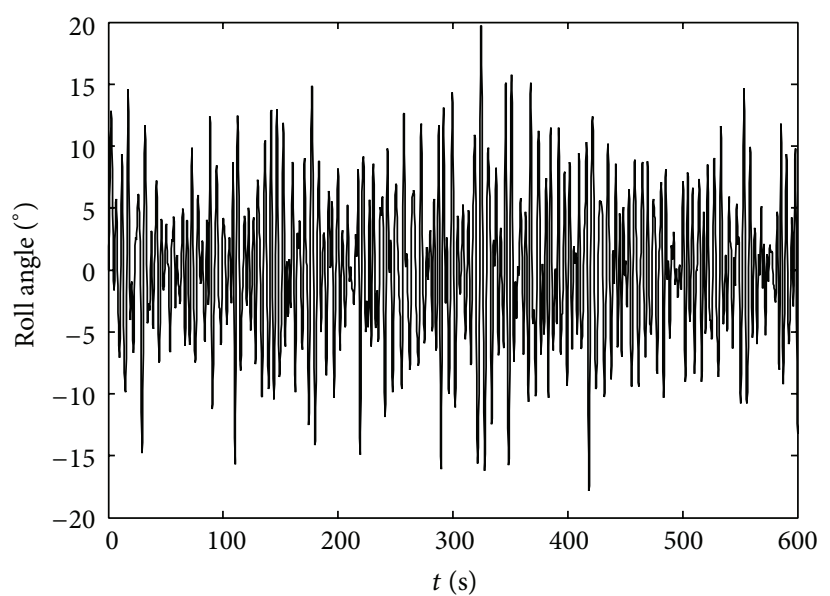

FIGURE 14: Simulation without roll control when $H_{s}=1.5 \mathrm{~m}$ and $\gamma=90^{\circ}$. 


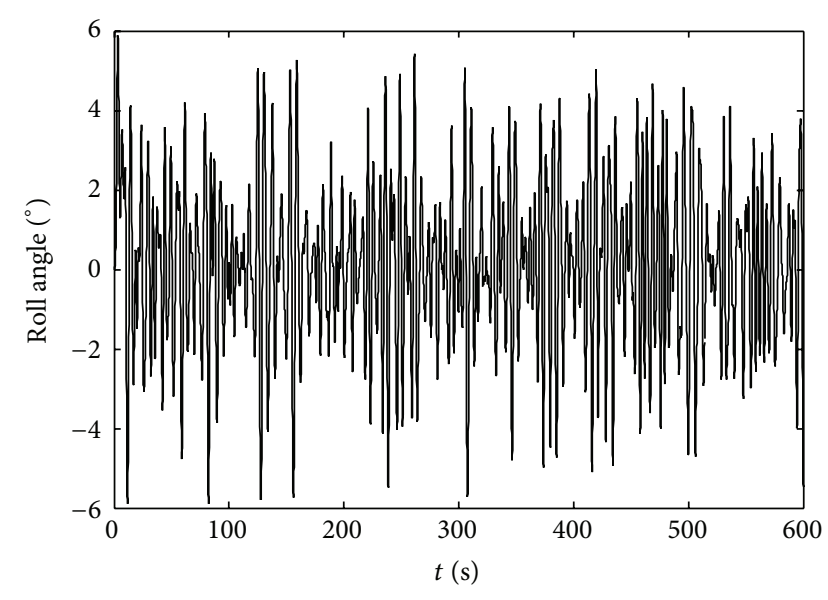

FIGURE 15: Simulation of roll with PID when $H_{s}=1.5 \mathrm{~m}$ and $\gamma=90^{\circ}$.

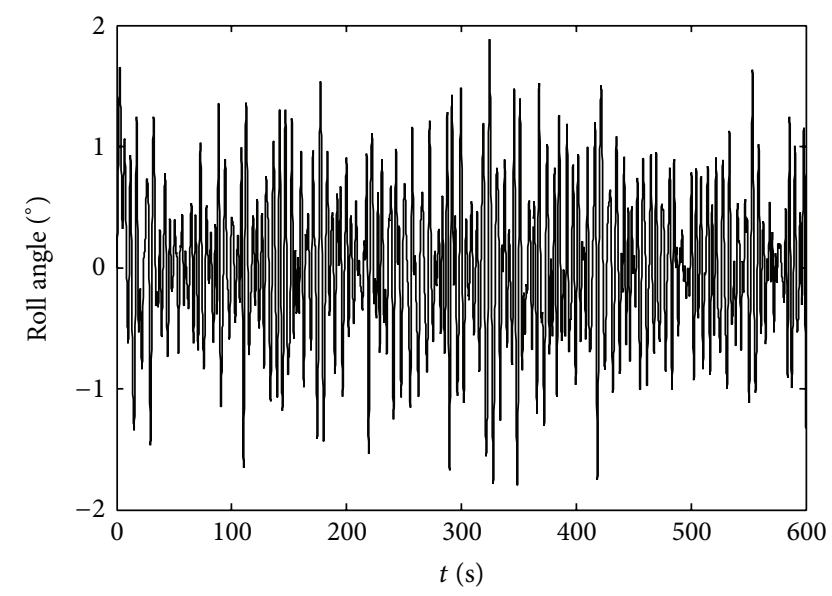

FIGURE 16: Simulation of roll with ADRFC when $H_{s}=1.5 \mathrm{~m}$ and $\gamma=90^{\circ}$.

\section{References}

[1] M.-C. Fang, P.-E. Chang, and J.-H. Luo, "Wave effects on ascending and descending motions of the autonomous underwater vehicle," Ocean Engineering, vol. 33, no. 14-15, pp. 19721999, 2006.

[2] W. Fan, J. Hongzhang, and Q. Zhigang, "Modeling for active fin stabilizers at zero speed," Ocean Engineering, vol. 36, no. 17-18, pp. 1425-1437, 2009.

[3] R. P. Dallinga, "Roll Stabilization of Motor Yacht: Hydrodynamic Aspects of the Comparison of Anti-roll Tanks and Fins," 2002, http://www.marin.nl/web/News/News-items/Rollstabilization-of-motor-yacht-Hydrodynamic-aspects-of-thecomparison-of-antiroll-tanks-and-fins.htm.

[4] H.-Z. Jin, Y.-M. Luo, Z.-G. Qi, and Z.-C. Yang, "Investigation of the lifting force of a zero speed fin stabilizer with Weis-Fogh mechanism," Journal of Harbin Engineering University, vol. 28, no. 7, pp. 762-767, 2007 (Chinese).

[5] X.-Z. Wang, H.-Z. Xu, J.-L. Sun, and D.-K. Feng, "Nonlinear robust controller design for ship steering in a seaway," Journal of Ship Mechanics, vol. 10, no. 6, pp. 35-42, 2006.
[6] L. X. Pan, Research on control strategy of AUV roll stabilizing near surface [Ph.D. thesis], Harbin Engineering University, 2010, (Chinese).

[7] H. Z. Jin, L. X. Pan, and L. L. Wang, "Adaptive variable structure control with neuron for low speed stabilizing of submarine near surface," Control and Decision, vol. 25, no. 4, pp. 562-571, 2010 (Chinese).

[8] H. Z. Jin, F. Wang, L. Ma, and Y. N. Gao, "Design a two-step master-slave control law for zero-speed fin stabilizers," Acta Automatica Sinica, vol. 38, no. 6, pp. 1059-1064, 2012 (Chinese).

[9] E. V. Lewis, Principles of Naval Architecture-Volume III, The Society of Naval Archtects and Marine Engineers, Jersey City, NJ, USA, 1988.

[10] P. M. Ostafichuk, AUVhydrodynamic and modeling for improved control [Ph.D. thesis], University of British Columbia, 2004.

[11] C. Erazo, F. Angulo, and G. Olivar, "Stability analysis of the extended state observers by Popov criterion," Theoretical and Applied Mechanics Letters, vol. 2, no. 4, Article ID 043006, 2012.

[12] Y. H. Wei, F. G. Peng, C. Sheng et al., "Control method of the stability of AUV," Journal of Huazhong University of Science and Technology (Natural Science Edition), vol. 42, no. 2, pp. 127-132, 2014.

[13] Z.-H. Ma, “The improvement of self-stable region approach for controlling uncertain systems," Control Theory \& Applications, vol. 26, no. 12, pp. 1391-1394, 2009.

[14] O.-S. Kwon, R. H. Choi, and D.-H. Lee, "Locomotion control of a compliant legged robot from slow walking to fast running," International Journal of Advanced Robotic Systems, vol. 9, article 240, 7 pages, 2012.

[15] X. Huo, Y. Yao, and K. Zheng, "Control design of a class of uncertain second-order systems via SSR and contingent cone criteria," Control and Decision, vol. 25, no. 6, pp. 831-835, 2010.

[16] Y. Gao, "Piecewise smooth Lyapunov function for a nonlinear dynamical system," Journal of Convex Analysis, vol. 19, no. 4, pp. 1009-1015, 2012. 


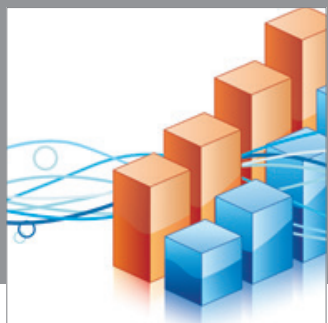

Advances in

Operations Research

mansans

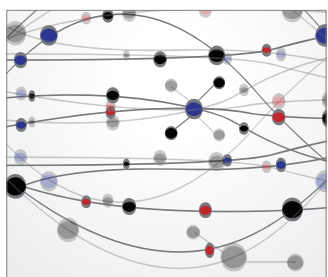

The Scientific World Journal
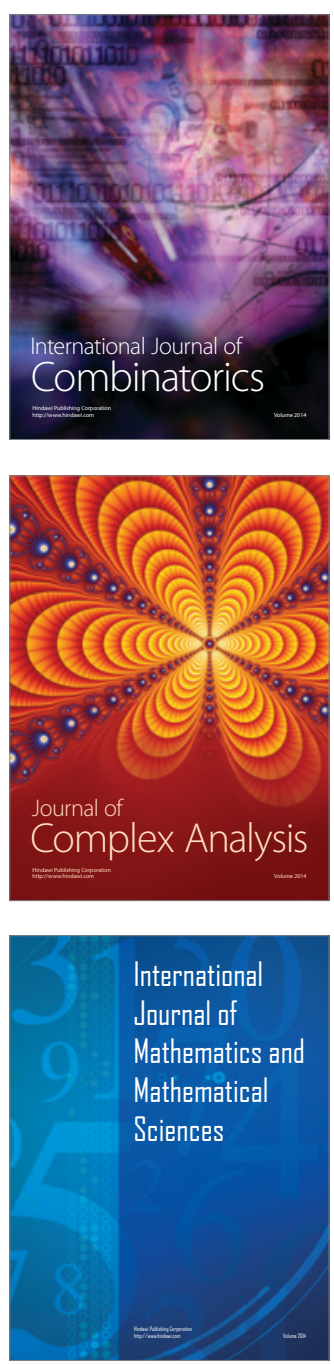
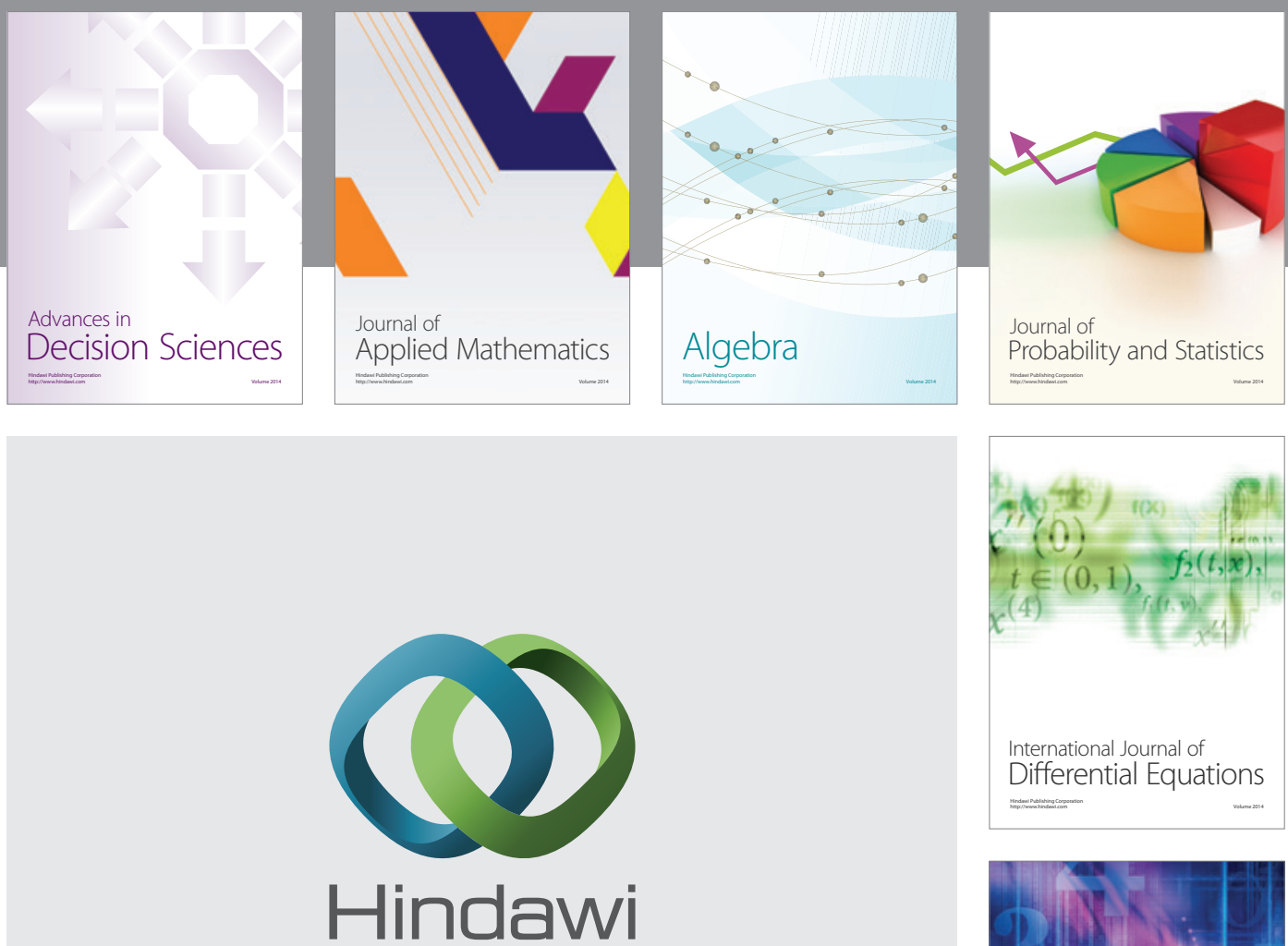

Submit your manuscripts at http://www.hindawi.com
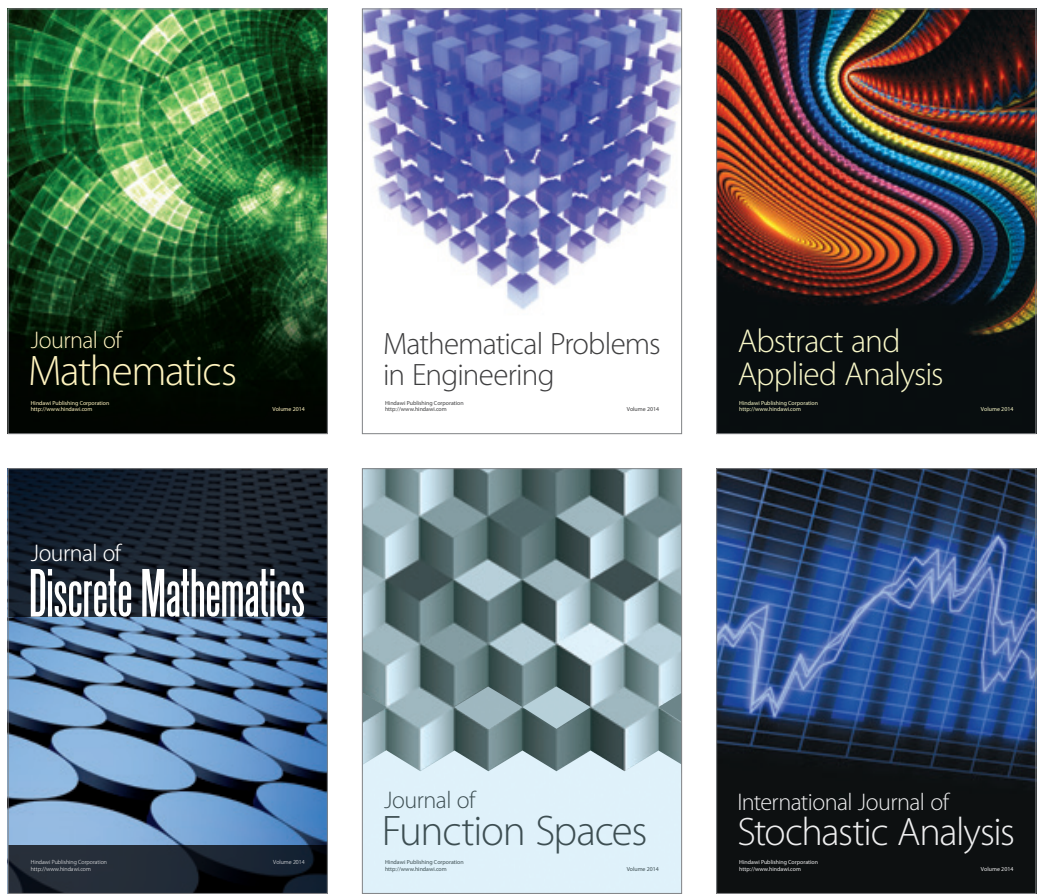

Journal of

Function Spaces

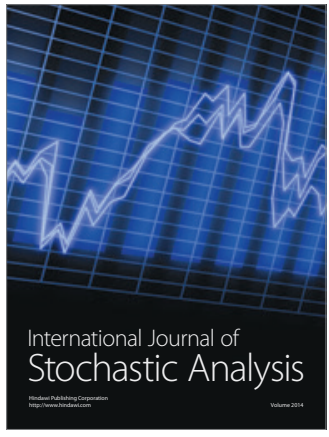

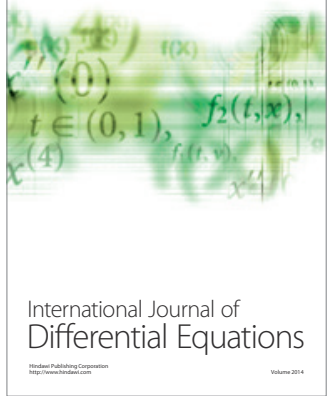
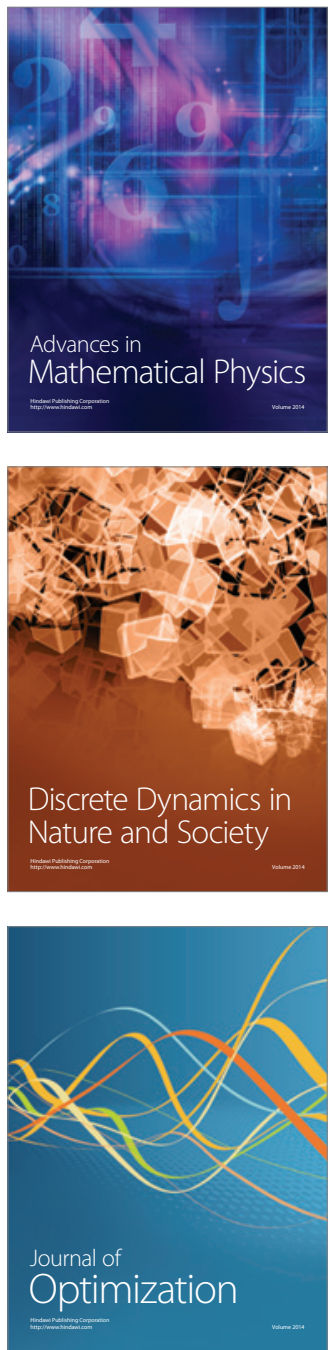